\title{
超微細球状黒鉛鋳鉄*1
}

糸藤春喜 $1, * 2$ 枝根和也 ${ }^{2} \quad$ 小谷友勝 3 板村正行 $4, * 3 \quad$ 安斎浩 -4

\author{
1 株式会社 $\mathrm{I} 2 \mathrm{C}$ 技研 \\ 2 株式会社ツチヨシ産業 \\ 3 ヤンマーキャステクノ株式会社 \\ 4 東北大学大学院 工学研究科 金属フロンティア工学専攻
}

J. Japan Inst. Met. Mater. Vol. 85, No. 4 (2021), pp. 147-154

(C) 2021 The Japan Institute of Metals and Materials

\section{Ultrafine Spheroidal Graphite Iron Castings}

Haruki Itofuji ${ }^{1, * 2}$, Kazuya Edane ${ }^{2}$, Tomokatsu Kotani ${ }^{3}$, Masayuki Itamura ${ }^{4}{ }^{* 3}$ and Koichi Anzai ${ }^{4}$

${ }^{1}$ I2C Technology Institute, Ube 755-0025

${ }^{2}$ Tsuchiyoshi Industry Co., Ltd., Onan 696-0403

${ }^{3}$ Yanmar Casting Technology Co., Ltd., Matsue 690-0025

${ }^{4}$ Department of Metallurgy, Graduate School of Engineering, Tohoku University, Sendai 980-8579

Gravity die casting of spheroidal graphite iron had been attempted controlling free nitrogen during preparing base molten iron, magnesium treatment, inoculation and pouring. In this study, the actual $\mathrm{CO} / \mathrm{SiO}_{2}$ reaction temperature of base molten irons was surveyed and magnesium treatment was conducted at that temperature. The mold was made of steel and the cavity size was thickness of $5.4 \mathrm{~mm}$ and diameter of $35 \mathrm{~mm}$. As the results, ultrafine graphite nodules were obtained without chill in as-cast condition. They were average diameter of $7 \mu \mathrm{m}$ and density count of over $3000 / \mathrm{mm}^{2}$. Knuckle for automobile was also cast taking the same procedure. Knuckle had no meager defect like shrinkage, chill etc. in as-cast conditions. The possibility of no chill has become extremely higher than former study. [doi:10.2320/jinstmet.J2020053]

(Received November 6, 2020; Accepted January 6, 2021; Published March 25, 2021)

Keywords: spheroidal graphite iron, gravity die casting, free nitrogen, ultrafine nodule, chill free, as-cast

1. 緒言

球状黒鉛鋳鉄鋳物の生産量は, 過去 40 年間, 右肩上がり の増加となっている1). 鉄系鋳物では, 唯一の傾向を示して いる (Fig. 1). 仮に, 球状黒鉛粒をごく小さく制御できたな ら, 引張特性, 疲労特性及び破壊勒性のような機械的性質 が，現状より高い值となる事が期待できる2).さらに，黒鉛 粒間距離が現状より短くなるために, 高い熱伝導率を示すと いったような物理的性質も期待できる。その結果として，新 しい用途が生まれ，生産量が更に増加すると考えられる。

従来, 薄肉砂型鋳物における鋳放し無チルは, 球状黒鉛粒 径 (Spheroidal Graphite Diameter; $\left.\mathrm{SG}_{\mathrm{D}}\right) 15 \mu \mathrm{m}$, 球状黒鉛粒数 (Spheroidal Graphite Number Density; $\mathrm{SG}_{\mathrm{N}}$ ) 900 個/ $\mathrm{mm}^{2}$ が限界 であった ${ }^{3)} . \mathrm{SG}_{\mathrm{D}}$ をさらに小さくし $\mathrm{SG}_{\mathrm{N}}$ を多くするために は, チル【セメンタイト $\left(\mathrm{Fe}_{3} \mathrm{C}\right) 】$ 】生成を避けつつ, 砂型よ り早い凝固冷却速度が必要となる。新規材料の開発のためた けでなく，鋳物工場の未来像を創生するためにも，多くの研 究者が球状黒鉛鋳鉄の金型鋳造に取り組んできた。しかし, 研究室レベルで成功した者はいたものの ${ }^{4-10)}$, 現場レベルで

\footnotetext{
*1 Mater. Trans. 60 (2019) 41-48 に掲載. 文献 25)-27) を追加.

*2 Corresponding author, E-mail: h.itofuji@keb.biglobe.ne.jp

*3 Present address: Ube 755-0151, Japan
}

の鋳放し無チルを達成した者は殆どいなかった ${ }^{7-9)}$.

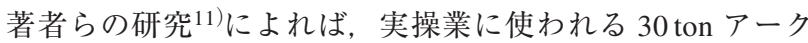

$$
70
$$

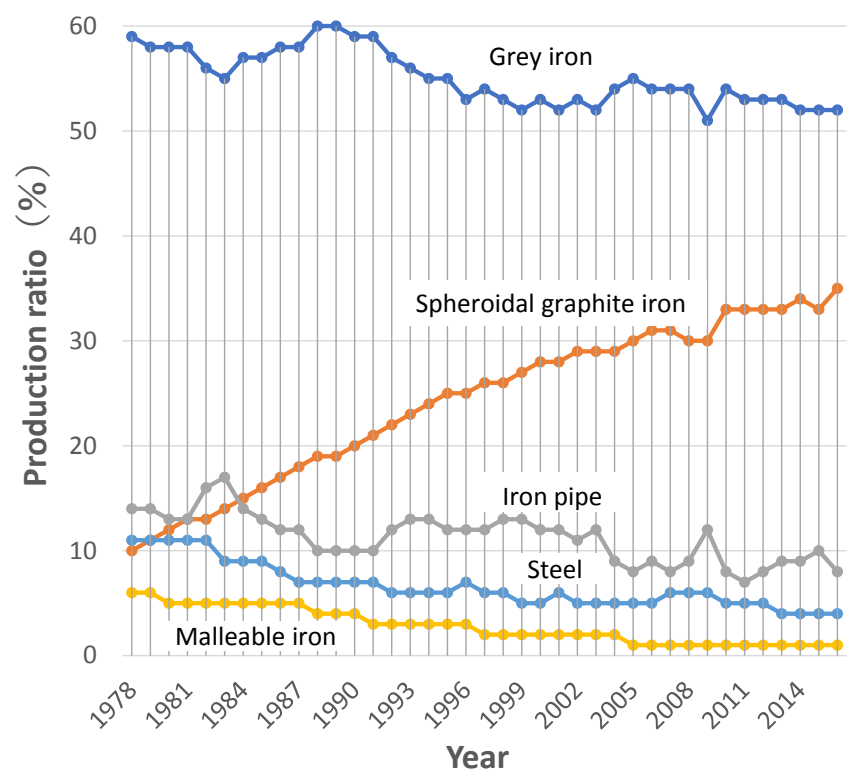

Fig. 1 Production ratio of ferrous castings for last four decades in Japan. 
炉においてフリー窒素 (Free nitrogen; $\mathrm{N}_{\mathrm{F}}$ ) と楔形試験片におけ るチル長との間に良い相関があることがわかっている．凝固 冷却速度が速い場合, $\mathrm{Fe}_{3} \mathrm{C}$ 結晶構造における炭素 $(\mathrm{C})$ 原子の 一部が窒素 $(\mathrm{N})$ 原子と置き換わり, $\mathrm{Fe}_{3}(\mathrm{C} \cdot \mathrm{N})$ を形成する可

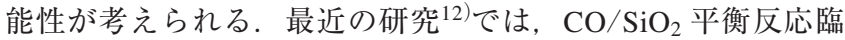
界温度 (Equilibrium $\mathrm{CO} / \mathrm{SiO}_{2}$ Reaction Critical Temperature; $\mathrm{T}_{\mathrm{EC}}$ )を考慮した溶解時間-温度スケジュールをチル対策に取 り入れている. しかし, 現場の溶解工程は, 非平衡となって いるため, 実際の $\mathrm{CO} / \mathrm{SiO}_{2}$ 反応臨界温度 $\left(\mathrm{T}_{\mathrm{AC}}\right)$ を考慮する必 要がある. 現在の同スケジュールは，十分とはいえない。さ らに，激しい反応を伴うマグネシウム $(\mathrm{Mg})$ 処理も考慮する 必要がある。

本研究では, 研究室のみならずと現場技術として安定した 条件となるような重力ダイカスト法の開発を試みた。

\section{2. 実 験 方 法}

Table 1 に示す原材料を $30 \mathrm{~kg}$ 高周波誘導炉を用いて溶解し た。溶解, $\mathrm{Mg}$ 処理, 接種及び鋳込みは, Fig. 2 に示す時間-
温度スケジュールに従って実施した。このスケジュールは, 既に，チル対策として報告済みのものである ${ }^{12)}$. 溶落ち後, 元湯を $1500^{\circ} \mathrm{C}$ 以上に過熱 (スーパーヒート)し，電力投入な しの自然冷却で $\mathrm{T}_{\mathrm{EC}}$ まで降温した。冷却の間，白銑サンプル を採取し発光分光分析機器により化学成分を分析した. $\mathrm{T}_{\mathrm{EC}}$ は，元湯の $\mathrm{C}$ と珪素 $(\mathrm{Si})$ 值を下式 ${ }^{13)}$ に代入して計算した。

$$
\begin{gathered}
\mathrm{T}_{\mathrm{EC}}\left({ }^{\circ} \mathrm{C}\right)=\mathrm{T}_{\mathrm{K}}-273 \\
\mathrm{~T}_{\mathrm{K}}=-27,486 /\left(\log \left[\mathrm{Si} / \mathrm{C}^{2}\right]-15.47\right)
\end{gathered}
$$

$\mathrm{T}_{\mathrm{EC}}$ 域では, 元湯表面に $\mathrm{SiO}_{2}$ 膜が生成し始める。この夕イミ ングで $\mathrm{K}$ 型熱電対を用いて計測し， $\mathrm{T}_{\mathrm{AC}}$ とした。溶湯を炉内 で自然冷却の間, 降温とともに N の溶解度が下がることから 脱 $\mathrm{N}$ が期待された ${ }^{8)} . \mathrm{Mg}$ 処理は， $\mathrm{T}_{\mathrm{AC}}$ にてプランジャーを用 いて溶解炉内で実施した(Fig. 3)。穏やかな処理反応とする ため, $\mathrm{Mg}$ 処理剂は, 可能な限り低い $\mathrm{Mg}$ 含有量のものとし た。高い $\mathrm{Mg}$ 含有量のものは, 反応が激しくチルを誘発させ る可能性がある ${ }^{9)} . \mathrm{Mg}$ 処理溶湯は, $\mathrm{Al}_{2} \mathrm{O}_{3} \cdot \mathrm{SiO}_{2}$ 製セラミッ ク取鍋に出湯した，その際，出湯流接種を実施した。これら 溶湯処理剂の化学成分及び処理量を Table 2 に示す. Mg 及び 接種処理溶湯は，接種後 $30 \mathrm{~s}$ 以内に, $\mathrm{Al}_{2} \mathrm{O}_{3} \cdot \mathrm{SiO}_{2}$ 製セラ

Table 1 Chemical composition of raw materials for gravity die castings

\begin{tabular}{|l|c|c|c|c|c|c|}
\hline \multirow{2}{*}{ Raw material } & \multicolumn{6}{|c|}{ Chemical composition (mass \%) } \\
\cline { 2 - 7 } & C & Si & Mn & P & S & A \\
\hline Pig iron & 3.69 & 1.02 & 0.11 & 0.025 & 0.006 & 0.009 \\
\hline Fe-Si & 0.10 & 75.03 & - & 0.026 & 0.004 & 1.340 \\
\hline Fe-S & - & - & - & - & 48.760 & - \\
\hline Carbon & 99.24 & - & - & - & 0.026 & - \\
\hline
\end{tabular}

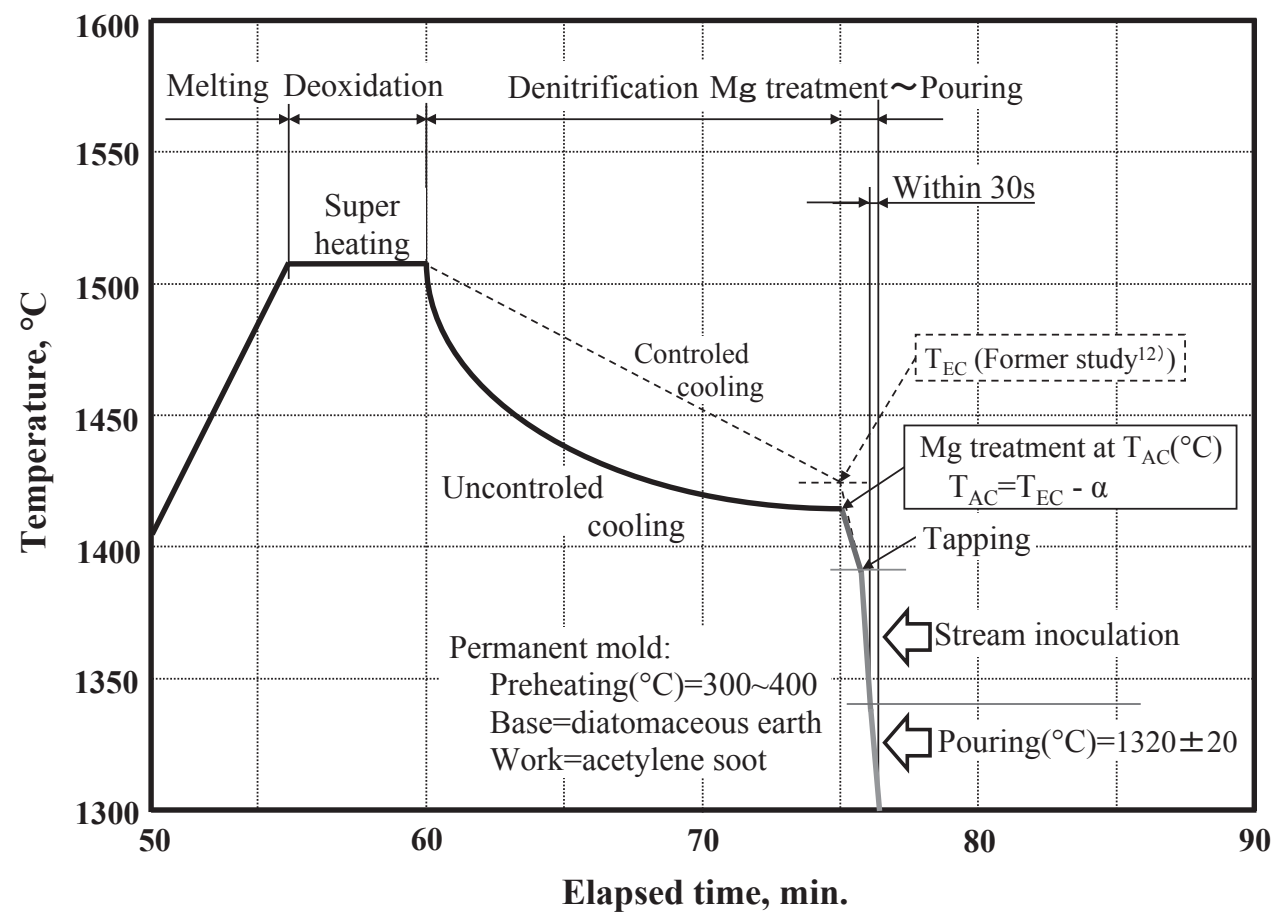

Fig. 2 Time-temperature schedule for melting, treatment, and pouring. 
ミック・スプーンを用いて予熱した金型に鋳込んだ。目標鋳 込み温度は, $1320 \pm 20^{\circ} \mathrm{C}$ とした。金型の形状・寸法12)を Fig. 4 に示す.この金型は, 本来, 発光分光分析用のもので あり，白銑試料を採取するためのものである．溶解現場で使 われる一般的な金型である。一方，実験に用いた重力ダイカ ストに用いた金型には，従来と同様9），チル軽減の基礎塗型 として水性珪藻土塗型を約 $0.4 \mathrm{~mm}$ 塗布し, 作業塗型として アセチレン・すすを約 $0.2 \mathrm{~mm}$ 塗布した。 その後, 金型は, 電気加熱炉にて $350^{\circ} \mathrm{C}$ に予熱した。鋳込んだ供試材は, $550^{\circ} \mathrm{C}$ 以下で金型から取出した。化学成分分析用白銑試料は, 鋳込み供試材と同一の溶湯から採取した。白銑試料は, 発光 分光分析器, 通称カントバックにて成分分析した。この機器 は, PDA 測光システム (Pulse Height Distribution Analysis System) を備えた発光分光分析装置であり，フリー Mg と介 在物 $\mathrm{Mg}$ を選り分ける分析が可能である。本実験では， $\mathrm{N}_{\mathrm{F}}$ 制 御により溶湯の黒鉛化能が極めて高くなっており，一般の金 型に鋳込んだとはいえレデブライト組織に多量の黒鉛粒が混 在している ${ }^{12)}$. このような状態では, 発光分光分析での $\mathrm{C}$ 及 び S の精度が低くなる。このため，これらに関しては，高周 波燃焼・赤外線吸収機器 (CS-LS600, Leco Corp.) でも分析 し，その值を採用することにした。

重力ダイカストで鋳込んだ供試材は, 堰から下方へとマイ クロ切断砥石で切断した。 その供試材を樹脂に埋め込んで研 磨し, 光学顕微鏡にて断面ミクロ組織を観察した. $\mathrm{SG}_{\mathrm{S}}$ と $\mathrm{SG}_{\mathrm{N}}$ は，写真撮影したミクロ組織から実測した。

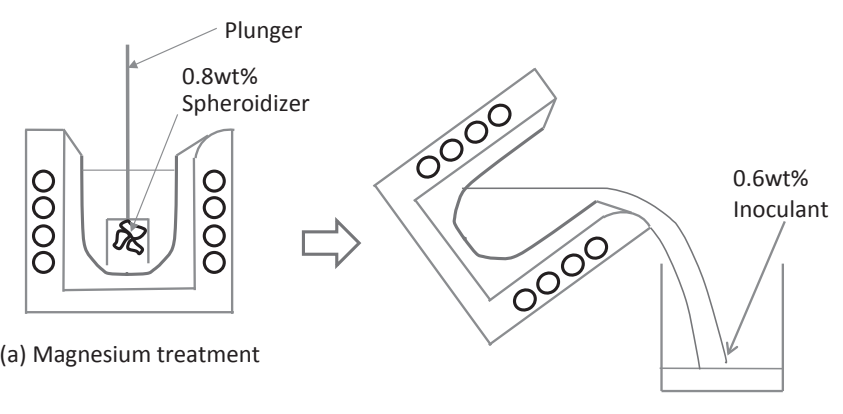

(b) Tap and stream inoculation

Fig. 3 Procedure of magnesium treatment and inoculation.
重力ダイカスト材のミクロ組織と比較するため，3 種類の 肉厚の異なる砂型鋳物を鋳込んだ。第 1 の対比供試材は, 肉 厚が $6.5 \mathrm{~mm}$ で重量 $130 \mathrm{~kg}$ の箱型鋳物である。第 2 は, JIS G

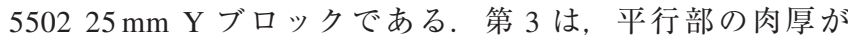
$100 \mathrm{~mm}$ の Y ブロックとした。これらに鋳込む元湯は, 10 ton 低周波誘導炬にて溶製した。溶解材料は，Table 3 に示すも のとした。溶湯処理は, Table 2 に示す処理剂と同じものを 使用した。

鋳放し無チル重力ダイカスト法の実現を探るため, 前述と 同じ要領で自動車用ステアリングナックルを鋳込んだ。その 品質は，外観，引け巣及びミクロ組織について調査した。鋳 造方案は, Fig. 5 に示すような無押し湯方案とし, 湯口棒と 堰を兼用とした。

\section{3. 実 験 結 果}

溶湯の化学成分を Table 4 に示す。式 ( 1 ) 及び式 ( 2 )を用 いて元湯の $\mathrm{C}$ 及び $\mathrm{Si}$ 值から $\mathrm{T}_{\mathrm{EC}}$ を求めると, $1425^{\circ} \mathrm{C}$ となっ た。元湯を $1540^{\circ} \mathrm{C}$ にスーパーヒートした後，電力を投入す ることなく自然冷却した結果, 約 $1415^{\circ} \mathrm{C}$ で $\mathrm{SiO}_{2}$ 膜が生成し 始めた. この温度をもって, $\mathrm{T}_{\mathrm{AC}}$ とした. $\mathrm{Mg}$ 処理は, 炉内 でプランジャーを用いて $1415^{\circ} \mathrm{C}\left(\fallingdotseq \mathrm{T}_{\mathrm{AC}}\right)$ にて実施した。 $\mathrm{T}_{\mathrm{EC}}$

ф3 Semicircle flow-off

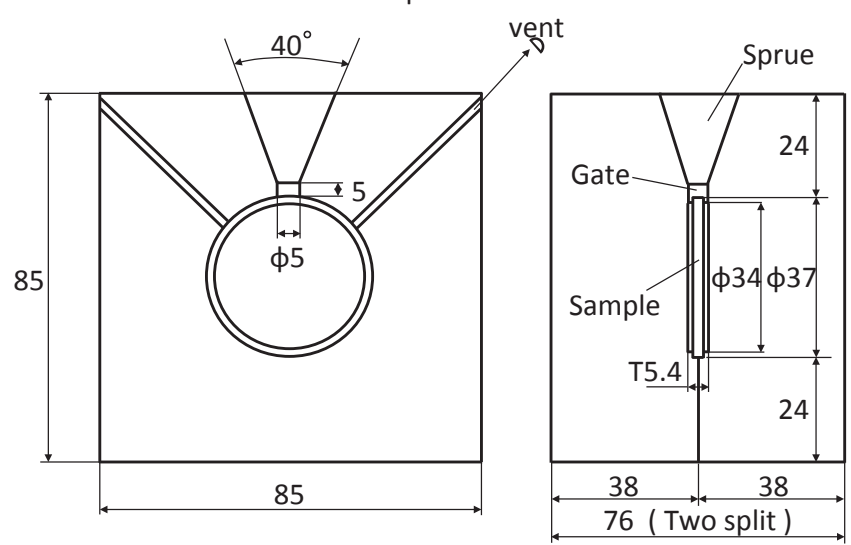

Fig. 4 Shape and dimensions of the medium-carbon steel gravity die (unit: $\mathrm{mm})^{12)}$.

Table 2 Chemical composition of agents and amount of their addition.

\begin{tabular}{|c|c|c|c|c|c|c|c|c|c|c||c|}
\hline \multirow{2}{*}{ Mold } & \multirow{6}{*}{ Agent } & \multicolumn{7}{|c|}{ Chemical composition (mass \%) } & \multicolumn{2}{|c||}{ Gas (mass ppm) } & Addition \\
\cline { 3 - 13 } & & $\mathbf{S i}$ & $\mathbf{M g}$ & $\mathbf{C a}$ & $\mathbf{R E}$ & $\mathbf{A l}$ & $\mathbf{C}$ & $\mathbf{B l}$ & $\mathbf{O}$ & $\mathbf{N}$ & (wt. \%) \\
\hline \multirow{3}{*}{ Permanent } & Spheroidizer & 44.08 & 3.85 & 0.66 & 1.43 & 0.38 & 1.97 & $\mathrm{Fe}$ & 767 & 8 & 0.8 \\
\cline { 2 - 14 } & Inoculant & 75.81 & - & 1.82 & - & 2.16 & - & $\mathrm{Fe}$ & 347 & 41 & 0.6 \\
\hline \multirow{3}{*}{ Sand } & Spheroidizer & 45.50 & 5.76 & 2.13 & 2.39 & 0.28 & - & $\mathrm{Fe}$ & 515 & 893 & 1.1 \\
\cline { 2 - 13 } & Inoculant & 76.20 & - & 1.78 & - & 2.21 & - & $\mathrm{Fe}$ & 3542 & 46 & 0.4 \\
\hline
\end{tabular}


Table 3 Chemical composition of raw materials for sand mold castings.

\begin{tabular}{|l|c|c|c|c|c|c|}
\hline \multirow{2}{*}{ Raw material } & \multicolumn{6}{|c|}{ Chemical composition (mass \%) } \\
\cline { 2 - 7 } & $\mathbf{C}$ & $\mathbf{S i}$ & $\mathbf{M n}$ & $\mathbf{P}$ & $\mathbf{S}$ & $\mathbf{A}$ \\
\hline Pig iron & 4.17 & 0.26 & 0.03 & 0.027 & 0.015 & tr. \\
\hline Steel scrap & 0.01 & 1.11 & 0.19 & 0.011 & 0.008 & tr. \\
\hline Fe-Si & 0.05 & 75.70 & tr. & 0.015 & 0.005 & 1.27 \\
\hline Fe-Mn & 6.73 & 0.36 & 76.50 & 0.120 & 0.017 & tr. \\
\hline Fe-S & - & - & - & - & 48.760 & - \\
\hline Carbon & 99.24 & - & - & - & 0.026 & - \\
\hline
\end{tabular}

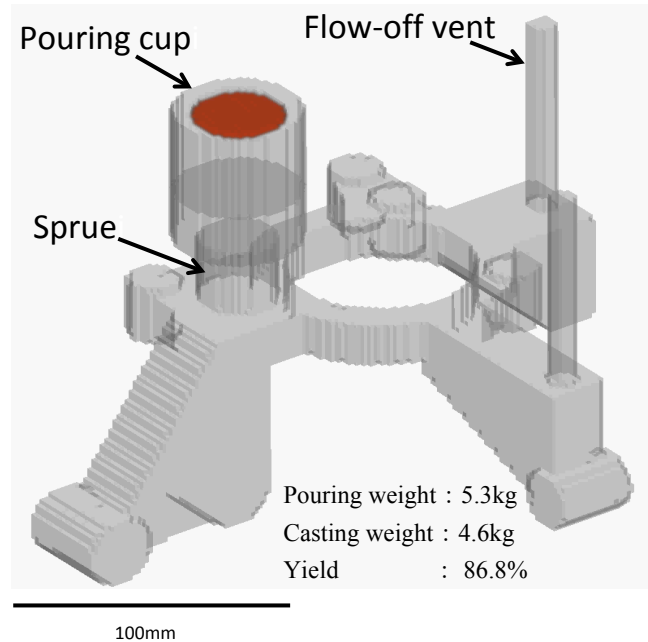

Fig. 5 Cast design of steering knuckle for automobile.
と $\mathrm{T}_{\mathrm{AC}}$ の差は, $15^{\circ} \mathrm{C}$ であった， $\mathrm{Mg}$ 反応が終了した直後に取 鍋に出湯し，その途中で出湯流接種を実施した。予熱金型へ は，セラミック・スプーンを使って $1340^{\circ} \mathrm{C}$ で鋳込んだ，接

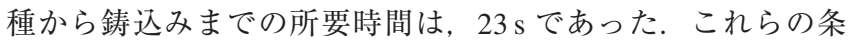
件は, ほかの 3 種類の砂型鋳物と合わせて Table 5 に示す. $\mathrm{t} 5.4 \mathrm{~mm} \times \Phi 30 \mathrm{~mm}$ 供試材の切断面に招けるマク口組織を Fig. 6 に示す．断面品質が識別しやすいように，ダイヤモン ド研磨し $3 \mathrm{Vol} \%$ ナイタールにて軽く腐食した。供試材が無 チルで黒鉛組織となった場合, Fig. 6(a)に示すように, 外引 け(クボミ凹)と内引け巣が観察された。堰の断面積が狭 かったことが要因として考えられる。これに対しチルが生成 した場合には，Fig. 6(b)に示すように，チルの柱状組織が識 別できるマクロ組織となった． $\mathrm{Mg}$ 処理及び接種後の溶湯化 学成分を Table 4 に示す. Mgは, 形態分析值で示してある. $\mathrm{Mg}_{\mathrm{F}}$ は，金属状態で，黒鉛球状化に関与すると考えられるフ リー $\mathrm{Mg}$ である ${ }^{14)} . \mathrm{Mg}_{\mathrm{T}}$ は, 従来の残留 $\mathrm{Mg}$ に相当し, フ

Table 4 Chemical composition of molten irons.

\begin{tabular}{|c|c|c|c|c|c|c|c|c|c|c|}
\hline \multirow{2}{*}{ Mold } & \multirow{2}{*}{\multicolumn{2}{|c|}{ Sample castings (mm) }} & \multicolumn{8}{|c|}{ Chemical composition ( mass \% ) } \\
\hline & & & $\mathrm{C}$ & $\mathrm{Si}$ & $\mathrm{Mn}$ & $\mathrm{P}$ & $\mathrm{S}$ & $\mathrm{Mg}_{\mathrm{F}}$ & $\mathrm{Mg}_{\mathrm{T}}$ & $\mathrm{CE}$ \\
\hline \multirow{4}{*}{ Permanent } & \multirow{2}{*}{ t5.4 x $\varphi 34$} & Base & 3.66 & 2.58 & 0.09 & 0.022 & 0.006 & - & - & 4.52 \\
\hline & & After treatment & 3.61 & 3.11 & 0.10 & 0.024 & 0.008 & 0.013 & 0.018 & 4.65 \\
\hline & \multirow{2}{*}{$\begin{array}{l}\text { Steering } \\
\text { knuckle }\end{array}$} & Base & 3.46 & 2.59 & 0.07 & 0.020 & 0.013 & - & - & 3.32 \\
\hline & & After treatment & 3.40 & 3.26 & 0.07 & 0.020 & 0.009 & 0.016 & 0.020 & 4.49 \\
\hline \multirow{6}{*}{ Sand } & \multirow{2}{*}{ t6.5 Thin wall box } & Base & 3.69 & 2.60 & 0.51 & 0.047 & 0.041 & - & - & 4.56 \\
\hline & & After treatment & 3.51 & 3.65 & 0.53 & 0.047 & 0.017 & 0.036 & 0.043 & 4.73 \\
\hline & \multirow{2}{*}{ 25-Y block } & Base & 3.55 & 1.48 & 0.21 & 0.039 & 0.020 & - & - & 4.04 \\
\hline & & After treatment & 3.42 & 2.66 & 0.21 & 0.038 & 0.013 & 0.031 & 0.037 & 4.31 \\
\hline & \multirow{2}{*}{ 100-Y block } & Base & 3.56 & 1.61 & 0.24 & 0.050 & 0.006 & - & - & 3.76 \\
\hline & & After treatment & 3.43 & 2.33 & 0.24 & 0.043 & 0.005 & 0.036 & 0.040 & 4.21 \\
\hline
\end{tabular}

$\mathrm{Mg}_{\mathrm{F}}=$ metallic magnesium $=$ Free magnesium, $\mathrm{Mg}_{\mathrm{T}}=$ total magnesium $=$ residual magnesium, $\mathrm{CE}=\mathrm{C}+1 / 3 \mathrm{Si}$ 
Table 5 Pouring condition in each heat.

\begin{tabular}{|c|c|c|c|c|c|c|c|c|}
\hline \multirow{2}{*}{ Mold } & \multirow{2}{*}{ Sample (mm) } & \multicolumn{6}{|c|}{ Temperature $\left({ }^{\circ} \mathrm{C}\right)$} & \multirow{2}{*}{$\begin{array}{l}\text { Elapsed } \\
\text { time after } \\
\text { inoculation } \\
\text { (s) }\end{array}$} \\
\hline & & $\begin{array}{c}\text { Super } \\
\text { heating }\end{array}$ & $\mathrm{T}_{\mathrm{EC}}$ & $\mathrm{T}_{\mathrm{AC}}$ & $\begin{array}{l}\mathrm{Mg} \\
\text { treatment }\end{array}$ & Inoculation & pouring & \\
\hline \multirow{2}{*}{ Permanent } & $\mathrm{t} 5.4 \times \mathrm{x} \Phi 34$ & 1540 & 1425 & 1409 & 1410 & 1386 & 1324 & 24 \\
\hline & Steering knuckle & 1517 & 1426 & 1410 & 1412 & 1374 & 1326 & 38 \\
\hline \multirow{3}{*}{ Sand } & t6.5 Thin wall box & 1507 & 1425 & 1408 & 1461 & 1461 & 1417 & 59 \\
\hline & 25 Y-block & 1483 & 1403 & 1387 & 1405 & 1405 & 1335 & 137 \\
\hline & 100 Y-block & 1478 & 1406 & 1391 & 1423 & 1423 & 1321 & 180 \\
\hline
\end{tabular}

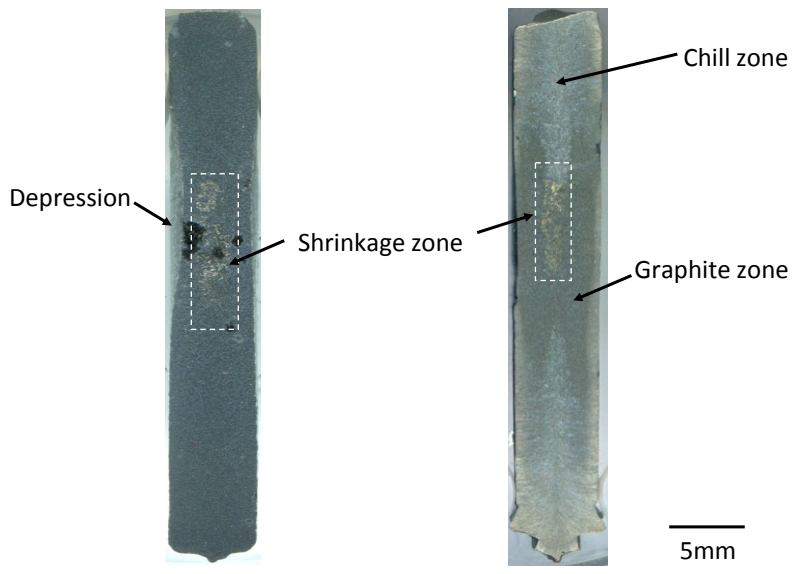

$\begin{array}{ll}\text { (a) Full graphite structure } & \text { (b) Mix structure of chill and graphite }\end{array}$

Fig. 6 Polished cross-sectional surfaces of as-cast sample castings.

リー Mg と介在物 $\mathrm{Mg}$ の総和を示すものである ${ }^{14)}$.

$\mathrm{t} 5.4 \mathrm{~mm} \times \Phi 30 \mathrm{~mm}$ ダイカスト供試材には, 無チルで全て球 状黒鉛から構成されるミクロ組織が観察された。その代表的 なミクロ組織を Fig. 7 (a) に示す. $S_{\mathrm{D}}$ は，4-9 $\mu \mathrm{m}$ の範囲の 超微細であった。 その平均粒径は, $7 \mu \mathrm{m}$ であった. 大きな黒 鉛粒径のものも観察されたが, それでも約 $15 \mu \mathrm{m}$ 程度であっ た。これらの比較的に大きな黒鉛粒のものは, 鋳込み中に晶
出した初晶黒鉛(過共晶) と考えられる。 $\mathrm{SG}_{\mathrm{N}}$ は, 3220 個/ $\mathrm{mm}^{2}$ であった。観察倍率を 500 倍とし，印刷後に全ての黒鉛 粒を手計算で実測した. $\mathrm{Mg}$ 処理温度を従来の $\mathrm{T}_{\mathrm{EC}}{ }^{12)}$ から $\mathrm{T}_{\mathrm{AC}}$ に変更したことにより，無チルで全黒鉛組織となる実験確率 が高くなった．従来の砂型鋳造品と比較するため， 3 種の異 なる供試材のミクロ組織を Fig. 7(b)-Fig. 7(d) に示す. この 対比は, 従来の $\mathrm{SG}_{\mathrm{D}}$ と $\mathrm{SG}_{\mathrm{N}}$ との違いを視覚的に理解しやす くしたものである. Fig. 7 に示した黒鉛組織の解析結果を Table 6 に示す. Fig. 7(b) は, チル（レデブライト)が生成し ない条件で黒鉛が晶出する従来の限界 $\mathrm{SG}_{\mathrm{N}}$ に近い. レデブラ イトは, $\Phi 3$ 半月状アガリ (兼, ガス抜き)にのみ観察された. そのミクロ組織を Fig. 8 に示す. $\mathrm{SG}_{\mathrm{N}}$ は, この供試材におい て最高の 3620 個 $/ \mathrm{mm}^{2}$ であった. レデブライトは, その面積 率が約 $25 \%$ で，共晶セル間に相当の領域に生成していた。

ステアリングナックルは, 出湯流接種から $38 \mathrm{~s}$ 後に $1326^{\circ} \mathrm{C}$ で予熱金型に鋳込んだ。溶湯充填時間は，6s であっ た。その後，ステアリングナックルが $500^{\circ} \mathrm{C}$ 以下となってか ら離型した。その鋳放し外観を Fig. 9（a)に示す。鋳肌は，目 視できるような $\mathrm{Mg}$ ドロス, 湯ジワ, 湯境等の欠陥は発生し ていなかった．ステアリングナックルは，Fig. 9(a)に示すA， B 及び C の個所で切断し，その切断面を目視観察した。 その 結果を Fig. 9(b)-Fig. 9(d)に示す.引け巣は, どの断面にも 観察されなかった。しかしながら, ガス穴が断面 Cの表面層 に観察された。 $\mathrm{SG}_{\mathrm{N}}$ は， 2240 個 $/ \mathrm{mm}^{2}$ 以上であった。断面 $\mathrm{B}$

Table 6 Results of microstructural analysis.

\begin{tabular}{|c|c|c|c|c|c|}
\hline Mold & $\begin{array}{l}\text { Sample } \\
(\mathrm{mm})\end{array}$ & $\begin{array}{l}\text { Diameter } \\
\text { Ave. }(\mu \mathrm{m})\end{array}$ & $\begin{array}{c}\text { Density } \\
\left(\text { Count } / \mathrm{mm}^{2}\right)\end{array}$ & $\begin{array}{c}\text { Nodularity } \\
(\%)\end{array}$ & $\begin{array}{c}\text { Perlite } \\
(\%)\end{array}$ \\
\hline \multirow{2}{*}{ Permanent } & t5.4 x Ф34 & 7 & 3220 & 94 & 70 \\
\hline & Steering knuckle & 9 & 2240 & 97 & 5 \\
\hline \multirow{3}{*}{ Sand } & t6.5 Thin wall box & 15 & 889 & 98 & 20 \\
\hline & 25 Y-block & 38 & 111 & 87 & 25 \\
\hline & 100Y-block & 78 & 34 & 88 & 20 \\
\hline
\end{tabular}




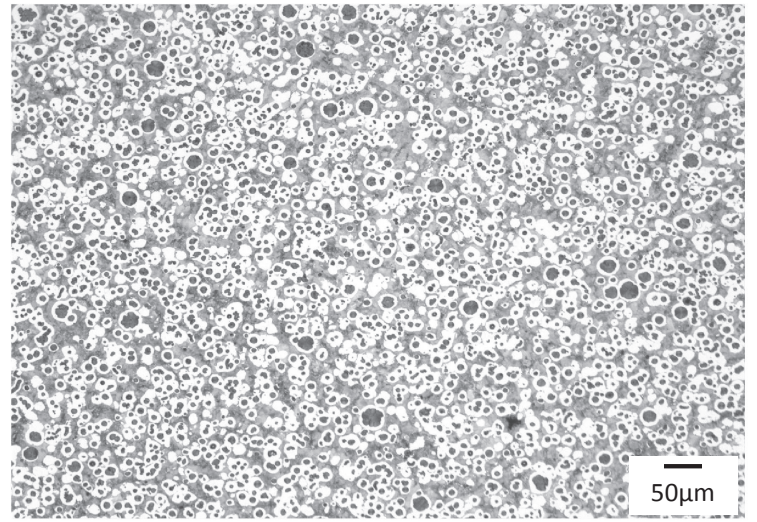

(a) $\Phi 35 \times \mathrm{t} 5.4 \mathrm{~mm}$ sample casting by die.

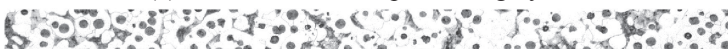
a *

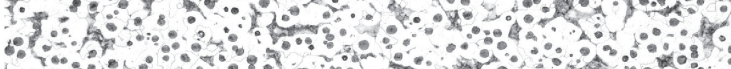

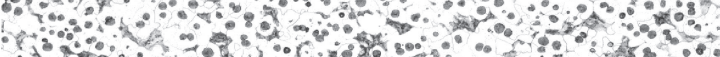

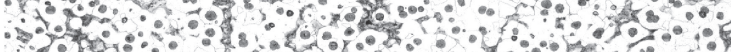
on

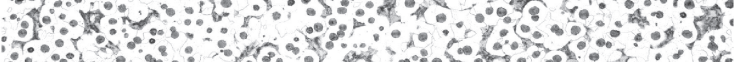

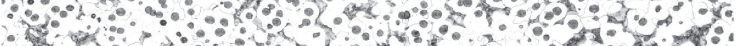
1.0.

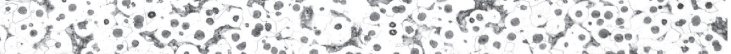
8000

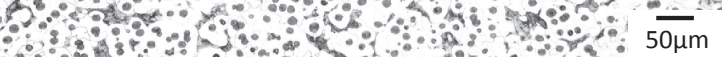

(b) ${ }^{t} 6.5 \mathrm{~mm}$ thin wall and $130 \mathrm{~kg}$ box type casting by sand mold

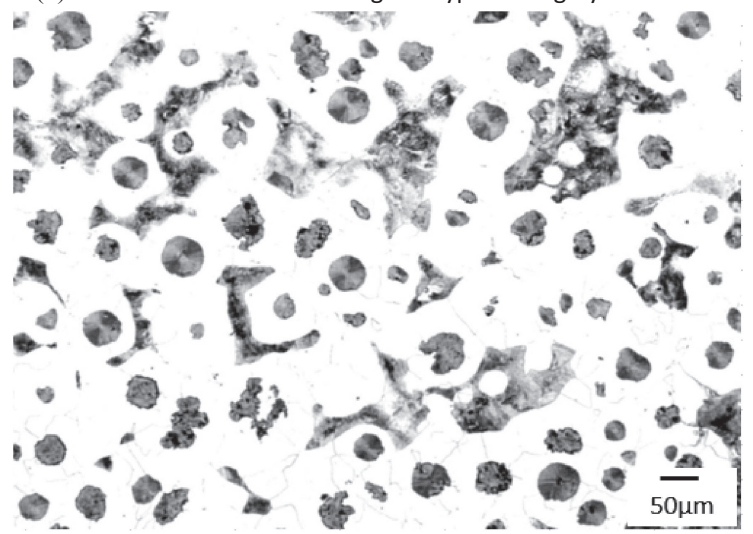

(c) $25 \mathrm{~mm}$ standard $Y$-block (JIS G 5502-2001) by sand mold ${ }^{13}$ )

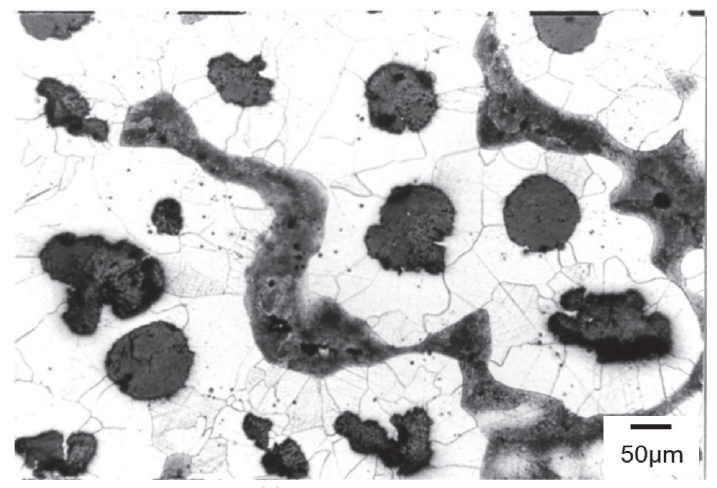

(d) $100 \mathrm{~mm}$ Y -block by sand mold

Fig. 7 Microstructures of die and sand mold castings.

におけるミクロ組織の事例を Fig. 10 に示す。これは，類似 ステアリングナックルの砂型品に観察される $\mathrm{SG}_{\mathrm{N}}{ }^{15)}$ の 10 倍 以上である。チルは，観察されていない。ミミロ組織解析の 結果を Table 6 に示す

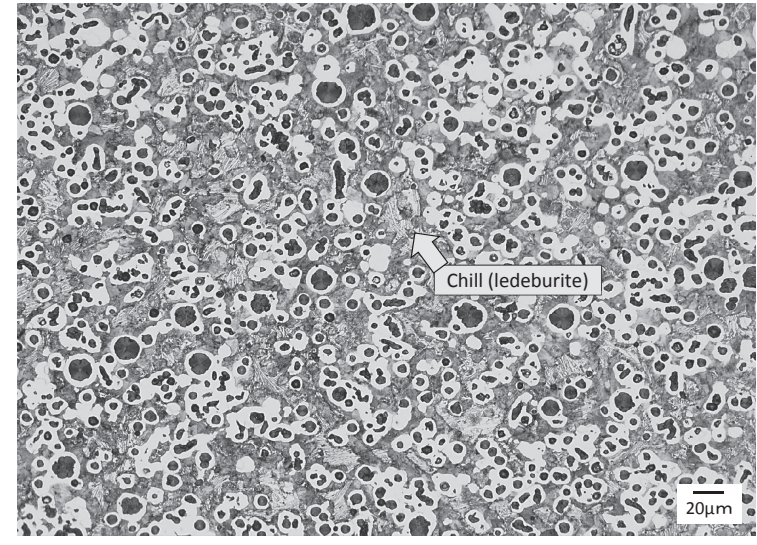

Fig. 8 Microstructure of $\Phi 3$ semicircle flow-off vent for sample casting (3 vol\% nital etch). $\mathrm{SG}_{\mathrm{N}}: 3620 \mathrm{count} / \mathrm{mm}^{2}$.
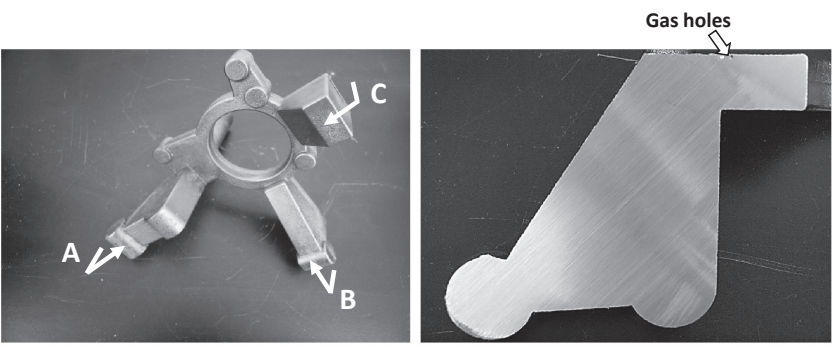

(a) As-cast appearance
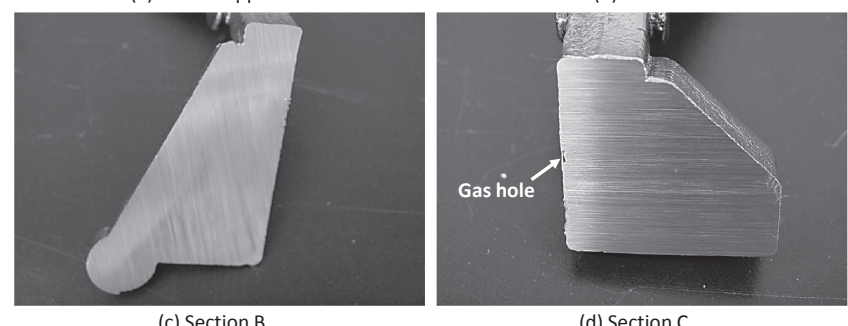

(d) Section C

Fig. 9 Quality of surface and cross-sections in steering knuckle by gravity die casting.

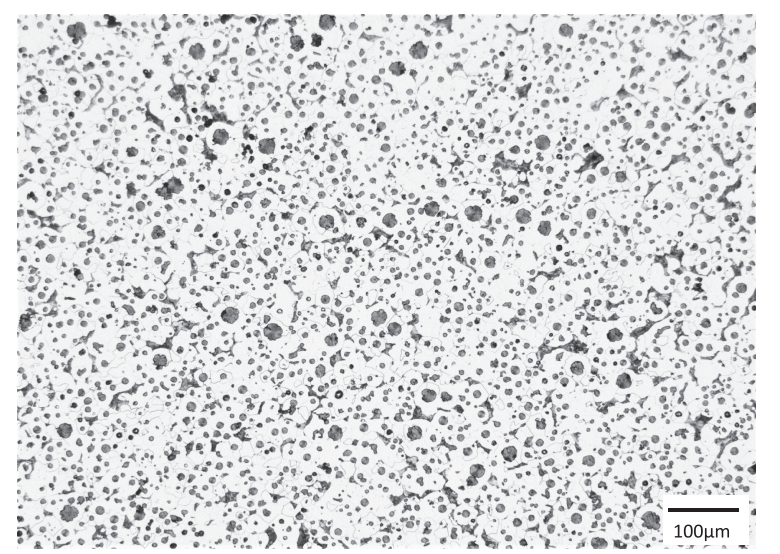

Fig. 10 Microstructure of surface layer at section B in steering knuckle, as shown in Fig. 9(a) (3 vol\% natal etch).

\section{4. 考察}

肉厚が薄くなるか或いは冷却速度が速くなると, $\mathrm{SG}_{\mathrm{D}}$ は微 細化し $\mathrm{SG}_{\mathrm{N}}$ は増加する。しかし，冷却速度が速すぎるとレデ 


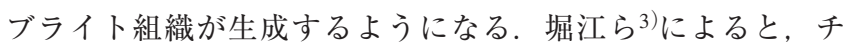
ル臨界冷却速度は，式（３）で与えられるとしている。 その際 の $\mathrm{SG}_{\mathrm{N}}$ は，およそ 900 個/ $\mathrm{mm}^{2}$ が限界と結論づけている.

$$
\begin{gathered}
\mathrm{SG}_{\mathrm{N}}=0.58 \mathrm{R}^{2}+19.07 \mathrm{R}+1.01 \\
\text { ここで, } \mathrm{R}=\text { 冷却速度 }\left({ }^{\circ} \mathrm{C} / \mathrm{s}\right)
\end{gathered}
$$

$\mathrm{SG}_{\mathrm{N}}$ が 900 個/ $\mathrm{mm}^{2}$ の時, $\mathrm{R}$ は, $26.2^{\circ} \mathrm{C} / \mathrm{s}$ となる。本実験で 無チル $\mathrm{SG}_{\mathrm{N}}$ の限界は, $\mathrm{t} 5.4 \mathrm{~mm} \times \Phi 30 \mathrm{~mm}$ 金型供試材で観察 されたチル無し 3200 個 $/ \mathrm{mm}^{2}$ とチル有り 3600 個 $/ \mathrm{mm}^{2}$ の間 にあると考えられる。この場合, チル臨界冷却速度は, 60$62^{\circ} \mathrm{C} / \mathrm{s}$ となる。従来の研究とは, 大きく異なり 2 倍以上の高 速まで無チルとなっている。この違いは，チル $\left(\mathrm{Fe}_{3} \mathrm{C}\right)$ 形成へ の $\mathrm{N}_{\mathrm{F}}$ の関与をイメージするか否かの理論にあろう。本研究 では， $\mathrm{N}_{\mathrm{F}}$ 制御をキーポイントと考えている．この概念は， 従来にはなかったことである。 $\mathrm{N}_{\mathrm{F}}$ は，スーパーヒート温度 からの徐冷で減少できる。さらに, アルミニウム $(\mathrm{Al})$, カル シウム $(\mathrm{Ca})$, 珪素 $(\mathrm{Si})$ 等を含む接種材の添加によって相殺で きる， $N_{F}$ と楔形試験片におけるチル深さとの間に良い相関 があることは，著者らによって実証され鋳造現場の実践に適 用されている11).

マンガン $(\mathrm{Mn})$ やクロム $(\mathrm{Cr})$ のような元素は, チル形成傾 向を促進することが一般に知られている。これらの元素は, 鋳鉄溶湯への窒素の溶解度を増加させることも知られてい る16)。逆に, C, Si 及び燐 (P) は, 鋳鉄溶湯への窒素の溶解度 を減少させ，チル形成を抑制する17,16). $\mathrm{Mn}$ 及び $\mathrm{Cr}$ は, $\mathrm{Fe} の$ 原子サイズと近いことから, $\mathrm{Fe}_{3} \mathrm{C}$ の $\mathrm{Fe}$ と置換しチルを促進 することも考えられる。ささらに，原子結合性の観点から， $\mathrm{Mn}, \mathrm{Cr}$ と C との結合性を示す電気㓌性度は, Fe と C のそれ より大きい8).この原子の置換に関して, 同様のことが酸素 (O) 及び $\mathrm{N}$ 原子についても考えられる. $\mathrm{N}_{\mathrm{F}}$ とチルは, $\mathrm{Fe}_{3} \mathrm{C}$ の $\mathrm{C}$ 原子を $\mathrm{N}$ 原子が置換することに関して関連があり，そ の置換によってチルを促進する。しかし，フリー酸素 $\left(\mathrm{O}_{\mathrm{F}}\right)$ は，チルを促進する可能性が低いことが，著者らの研究によ りわかっている ${ }^{11)}$ ＳＳは，吸 $\mathrm{N}$ とチル形成を抑制するのに効 果があるものの ${ }^{18)}$ ，黒鉛球状化を阻害する元素でもある.

$\mathrm{Mg}$ は, 大気圧の下で約 $1100^{\circ} \mathrm{C}$ で気化する. $\mathrm{Mg}$ 原子は, Fe 原子に比べサイズが大きいことから，鋳鉄溶湯に殆ど溶解 度を持たない。その結果，気化した $\mathrm{Mg}$ は， $1300^{\circ} \mathrm{C}$ 以上で扱
われる鋳鉄溶湯にあって気泡で存在することができる. $\mathrm{Mg}$ 気泡の大きさは, 式( 4 ) 20) と式( 5 )によって求められる. 算出した $\mathrm{Mg}$ 気泡サイズを Table 6 に示す. Fig. 10 に示した 球状黒鉛粒は, その平均粒径が $7 \mu \mathrm{m}$ であった。このサイズ は, $1400-1450^{\circ} \mathrm{C}$ で $\mathrm{Mg}$ 処理した時の $\mathrm{Mg}$ 気泡サイズの計算 結果に近い19). Table 7 は，仮に別の方法で鋳放し無チルが得 られるとするなら，本研究より溶湯深さが浅く，且つ高温 $\mathrm{Mg}$ 処理の場合ほど気泡径を小さくできることを示している.

$\mathrm{Mg}$ の気化圧力 $(\mathrm{atm}) ; P_{\mathrm{Mg}}$

$\log P_{\mathrm{Mg}}=4.958-(1.229 \times 104) / T$

$T$ ；ランキン温度 $=1.8 \times$ 絶対温度 $\mathrm{K}$

$\mathrm{Mg}$ 気泡の直径 $(\mu \mathrm{m}) ; D$

$$
\begin{aligned}
P_{\mathrm{Mg}}= & P_{\mathrm{a}}+\rho g H+4 \gamma / D \\
D= & 4 \gamma /\left(P_{\mathrm{Mg}}-P_{\mathrm{a}}-\rho g H\right) \\
P_{\mathrm{a}} & ; \text { 大気圧 }(1 \mathrm{~atm}) \\
\rho & ; \text { 密度 }\left(6.8 \mathrm{~g} / \mathrm{cm}^{3}\right) \\
g & ; \text { 重力加速度 }\left(980 \mathrm{~cm} / \mathrm{s}^{2}\right) \\
H & ; \text { 溶湯梁さ }(\mathrm{cm}) \\
\gamma & ; \text { 表面張力 }(1450 \mathrm{dyne} / \mathrm{cm})
\end{aligned}
$$

P. Kainzinger らは21)，砂型鋳造した場合の $\mathrm{SG}_{\mathrm{D}}$ が小さく $\mathrm{SG}_{\mathrm{N}}$ が多いほど疲労強度が向上するとしている．彼らの研究 では, $\mathrm{SG}_{\mathrm{N}}$ が 20-250 個/ $\mathrm{mm}^{2}$ の供試材が扱われている。本実 験で得られた $\mathrm{SG}_{\mathrm{D}}$ 及び $\mathrm{SG}_{\mathrm{N}}$ からすると，さらに大きな疲労 強度の改善が期待される。ささらに, 従来の黒鉛粒間距離より 破格に狭いことから，熱伝導率も大きな改善が期待される.

$\mathrm{SG}_{\mathrm{D}}$ 及び $\mathrm{SG}_{\mathrm{N}}$ に加えて，ステアリングナックルにおいて 鋳放し無チルの完全黒鉛組織は，鋳鉄材料として信頼できる としなければならない．球状黒鉛鋳鉄鋳物の金型鋳造を熱処 理なしで成功した研究機関は, 幾つかある7,9,22,23). しかし, 鋳物工場の実践に転じたとの報告は，今のところ殆どない. 幾つかの鋳造工場で取り組んでいるものの, チル(レデブラ イト組織)の黒鉛化熱処理を実施している $5,6,24)$.このような チル化した鋳物の熱処理による黒鉛化は, $\mathrm{Mg}$ を含有するこ とから可鍛鋳鉄の場合より短く, $15 \mathrm{~min}$ 程度で良いとされて いる。しかしながら，球状化率が低い，黒鉛粒が不連続割れ のように直線状に並ぶ等，好ましくない黒鉛組織を形成する 可能性が高い10). これらの好ましからざる黒鉛組織は, $\mathrm{Mg}$

Table 7 Calculated diameter of magnesium gas bubbles in molten iron treated with magnesium spheroidizer.

\begin{tabular}{|c|c|c|c|c|c|}
\hline \multirow{2}{*}{$\begin{array}{c}\text { Temperature } \\
\left({ }^{\circ} \mathrm{C}\right)\end{array}$} & \multirow{2}{*}{$\begin{array}{c}\text { Vapore } \\
\text { presure } \\
(\text { atom })\end{array}$} & \multicolumn{5}{|c|}{$\begin{array}{r}\text { Bubble diameter at molten iron depth } \mathrm{D} \\
(\mu \mathrm{m})\end{array}$} \\
\cline { 3 - 7 } & & $\mathrm{D}=1 \mathrm{~cm}$ & $\mathrm{D}=10 \mathrm{~cm}$ & $\mathrm{D}=100 \mathrm{~cm}$ & $\mathrm{D}=500 \mathrm{~cm}$ \\
\hline 1300 & 4.15 & 17 & 17 & 21 & $*$ \\
\hline 1350 & 5.64 & 12 & 12 & 13 & 40 \\
\hline 1400 & 7.53 & 8 & 8 & 9 & 16 \\
\hline 1450 & 9.89 & 6 & 6 & 7 & 10 \\
\hline 1500 & 12.79 & 5 & 5 & 5 & 6 \\
\hline 1550 & 16.32 & 3 & 3 & 4 & 4 \\
\hline 1600 & 20.54 & 3 & 3 & 3 & 3 \\
\hline
\end{tabular}


ボイドの分布に起因している. $\mathrm{Mg}$ 気泡は, 針状レデブライ トを構成するオーステナイト $(\gamma)$ と $\mathrm{Fe}_{3} \mathrm{C}$ との間のサイトに位 置する ${ }^{20)}$. 球状の $\mathrm{Mg}$ 気泡は, このレデブライト組織に沿っ て分布し不規則形状のボイドとなる。線状分布にもなりえ る. 燒き戻し黒鉛は，このボイドに析出する25-27). 黒鉛粒の 線状分布は, 機械的性質, 特に疲労強度に影響を及ぼすであ ろう。

チル抑制 (黒鉛化促進)のための $\mathrm{N}_{\mathrm{F}}$ 説 $\left.11,12,28\right)$ と黒鉛球状化 理論「サイト説 29-32)」は, 鋳放し無チルの超微細球状黒鉛鋳 鉄鋳物の実践製造に適用できることを確認した。さらに安定 した製造条件を確立するため，既報の砂型鋳造11) と同様に, 重力ダイカストについても工程に対する $\mathrm{N}_{\mathrm{F}}$ の推移を分析し, チルとの関連を実証の予定である.

\section{5. 結 論}

$\mathrm{N}_{\mathrm{F}}$ 制御をイメージした重力ダイカストを実施した結果, 以下に示す結論を得た。

(1) $\mathrm{t} 5.4 \mathrm{~mm} \times \Phi 30 \mathrm{~mm}$ 及びステアリングナックル供試材と

もに，鋳放し完全無チル組織とすることができた.

（2） $\mathrm{t} 5.4 \mathrm{~mm} \times \Phi 30 \mathrm{~mm}$ 供試材では,平均 $\mathrm{SG}_{\mathrm{D}}=7 \mu \mathrm{m}$ を得た. ステアリングナックル供試材では, 平均 $\mathrm{SG}_{\mathrm{D}}=9 \mu \mathrm{m}$ を得た これらは, 従来, 報告例がない超極細粒である.

（3）無チル完全黒鉛組織を得るための条件の 1 つである $\mathrm{Mg}$ 処理温度は， $\mathrm{T}_{\mathrm{AC}}$ より $\mathrm{T}_{\mathrm{EC}}$ の方が安定した結果が得られる.

\section{文献}

1) Sokeizai Center: Material year book (2017).

2) P. Kainzinger and F. Grun: Giesserei Rundschau 61 (2014) Nr.11+12, s347-351.

3) H. Horie: Imono 67 (1995) 124-132.

4) H. Sakurai, M. Kawasaki and K. Ozaki: Technical Paper 945189, FISTA Congress (1994).

5) Y.S. Lerner: Foundry Management \& Technology, Oct. (2003) pp. $18-22$

6) A. Urrestarazu, J. Sertucha, R. Suárez and I. Álvarez-Ilzarbe: Rev. Metal. 49 (2013) 325-339.

7) Y. Lee, P. Kim, K. Hara, T. Sawamoto, N. Inoyama and Y. Kawano: Imono 55 (1983) 156-163.

8) N. Inoyama, S. Yamamoto and Y. Kawano: Cast Irons clarified Through Bonds and Reactions (1992).

9) T. Kitsudou, K. Ashida and K. Fujita: Imono 62 (1990) 359-364.

10) Permanent Mold Casting of Irons: Japan Foundry Society (1976).

11) H. Itofuji, M. Tamura, Moritake, M. Itamura and K. Anzai: Imono, $163^{\text {rd }}$ conference $(2013)$ p. 99.

12) H. Itofuji, K. Kazuya, T. Kotani, M. Itamura and K. Anzai: Proceedinds of CastTec2016 (2016).

13) B. Marineki: Mod. Cast. 42 (1962) 99

14) H. Itofuji: Int. J. Cast. Met. Res. 12 (1999) 179-187.

15) K. Edane, Y. Ameku, Y. Kurokawa, H. Itofuji, M. Itamura and K. Anzai: Imono, $168^{\text {th }}$ conference (2016) p. 151.

16) R.D. Pehlke: Trans. Met. Soc. AIME 218 (1960) 1088-1101.

17) K. Taniguchi: Tetsu-to-Hagané 18 (1932) 952-980.

18) T. Choh and M. Inoue: Tetsu-to-Hagané 54 (1968) 19.

19) P.K. Trojan and R.A. Flinn: Trans. ASM 54 (1961) 549-566.

20) H. Itofuji: Int. J. Cast. Met. Res. 17 (2004) 220-228.

21) P. Kainzinger and F. Grun: Giesserei Rundschau 61 (2014) Nr.11+12, s347-351

22) M.S.C. Rao and M.N. Srinivasan: AFS Trans. 96 (1988) PP79-PP89.

23) K.G. Davis, J.G. Magny, D.A. Brown and D. Hui: Advanced Casting Technology, Proc. Conf. Kalamazoo, MI Nov 12-14 (1986) pp. 221-230.

24) H. Sakurai, M. Kawaguti and K. Osaki: The Integration of Design and Manufacture (1994) pp. 55-61.

25) Y.-H. Lee and Y. Kawano: J. Japan Inst. Metals 44 (1980) 339-345.

26) K. Hanawa, K. Akechi, Z. Hara and T. Nakagawa: J. Japan Inst. Metals 44 (1980) 943-948.

27) Y.-H. Lee and Y. Kawano: J. Japan Inst. Metals 45 (1981) 948-956.

28) H. Itofuji, K. Edane, Y. Kurokawa, M. Itamura and K. Anzai: Imono, $168^{\text {th }}$ conference $(2016)$ p. 148.

29) H. Itofuji: Doctoral Thesis, Kyoto University, (1993).

30) H. Itofuji: AFS Trans. 104 (1996) 79-87.

31) H. Itofuji: Imono 84 (2012) 194-202.

32) H. Itofuji: Imono 90 (2018) 587-593. 